\title{
Development and validation of an ultra-performance liquid chromatography quadrupole time of flight mass spectrometry method for rapid quantification of free amino acids in human urine
}

\author{
Richard Joyce $^{1,2} \cdot$ Viktorija Kuziene $^{1} \cdot$ Xin Zou $^{1} \cdot$ Xueting Wang $^{1} \cdot$ Frank Pullen $^{3} \cdot$ \\ Ruey Leng Loo ${ }^{1}$
}

Received: 16 June 2015 / Accepted: 17 August 2015 / Published online: 29 August 2015

(C) The Author(s) 2015. This article is published with open access at Springerlink.com

\begin{abstract}
An ultra-performance liquid chromatography quadrupole time of flight mass spectrometry (UPLC-qTOFMS) method using hydrophilic interaction liquid chromatography was developed and validated for simultaneous quantification of 18 free amino acids in urine with a total acquisition time including the column re-equilibration of less than $18 \mathrm{~min}$ per sample. This method involves simple sample preparation steps which consisted of 15 times dilution with acetonitrile to give a final composition of $25 \%$ aqueous and $75 \%$ acetonitrile without the need of any derivatization. The dynamic range for our calibration curve is approximately two orders of magnitude (120-fold from the lowest calibration curve point) with good linearity $\left(r^{2} \geq 0.995\right.$ for all amino acids). Good separation of all amino acids as well as good intra- and inter-day accuracy $(<15 \%)$ and precision $(<15 \%)$ were observed using three quality control samples at a concentration of low, medium and high range of the calibration curve. The limits of detection (LOD) and lower limit of quantification of our method were ranging from approximately $1-300 \mathrm{nM}$ and $0.01-0.5 \mu \mathrm{M}$, respectively. The stability of amino acids in the prepared urine samples was found to be stable for $72 \mathrm{~h}$ at $4{ }^{\circ} \mathrm{C}$, after one freeze thaw cycle and for up to 4 weeks at $-80{ }^{\circ} \mathrm{C}$. We have applied this method to quantify the
\end{abstract}

Handling Editor: D. Tsikas.

Ruey Leng Loo

r.loo@kent.ac.uk

1 Medway Metabonomics Research Group, Medway School of Pharmacy, Universities of Kent and Greenwich, Kent, UK

2 RJMS Consultancy, Rochester, Kent, UK

3 Medway Metabonomics Research Group, School of Science, University of Greenwich, Kent, UK content of 18 free amino acids in 646 urine samples from a dietary intervention study. We were able to quantify all 18 free amino acids in these urine samples, if they were present at a level above the LOD. We found our method to be reproducible (accuracy and precision were typically $<10 \%$ for QCL, QCM and QCH) and the relatively high sample throughput nature of this method potentially makes it a suitable alternative for the analysis of urine samples in clinical setting.

Keywords Free amino acids · Human urine $\cdot$ Absolute quantification $\cdot$ HILIC-UPLC-qTOF-MS

\section{Introduction}

An optimal level of amino acids in the body is important for normal homeostasis. They are involved in the regulation of gene expression, cell metabolism and signalling and the biosynthesis of hormones (Wu 2009). The detection and quantification of free amino acids has been routinely applied for the diagnosis of new born with inborn error diseases (Piraud et al. 2011; Giordano et al. 2012). More recently, increasing literature has implicated the role of free amino acids in a number of diseases such as cardiovascular diseases (Batch et al. 2014), insulin resistance and type 2 diabetes (Lu et al. 2013), obesity (Morris et al. 2012; Wiklund et al. 2014), renal diseases (Batch et al. 2014; Kim et al. 2014; Niewczas et al. 2014), hepatic disorders (Fitian et al. 2014; Zhou et al. 2014) and a number of cancer-related disorders (Ma et al. 2014; Zang et al. 2014). The increased interest in free amino acids has prompted the need for a reliable and high-throughput simultaneous quantification of free amino acids in biological fluids. 
Fig. 1 Effect of modification of the Quadrupole RF settings for Ala and Gly

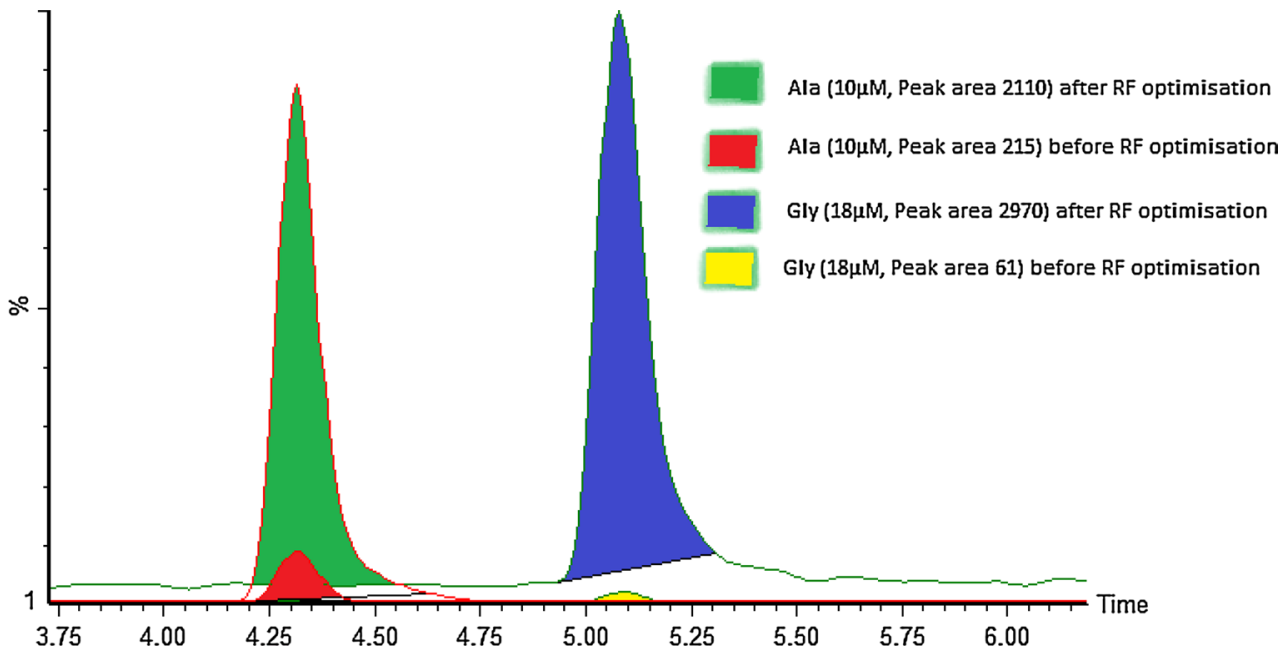

et al. 2007). Hydrophilic interaction liquid chromatography (HILIC) improves the retention of polar compounds and offers the potential for a successful method for the analysis of amino acids in complex biological matrices without the need of derivatization or ion-pairing agents. Indeed, the use of HILIC coupled with MS detection for the analysis of amino acids, in plant and cellular extracts, as well as in biological fluids such as serum, plasma and urine has been successfully applied (Langrock et al. 2006; Paglia et al. 2012; Yuan et al. 2012; Buiarelli et al. 2013; Guo et al. 2013; Zhou et al. 2013).

The guidance on bioanalytical method validation provided by the Food and Drug Administration (FDA) requires the demonstration of the reproducibility of a method in terms of its accuracy, precision and stability, when any modification to an existing method is made (US Food and Drug Administration 2001). In this study, we apply the same HILIC-based chromatographic method previously developed for the analysis of free amino acids in plant extracts as described by Guo et al. Instead of using a triple quadrupole LC-MS/MS method with targeted detection by multiple reaction monitoring (MRM) for quantitative analysis of these free amino acids, we apply a full scan LC-MS method using a qTOF. Here, we present and describe the development and validation of a UPLC-qTOF-MS method using HILIC conditions for simultaneous absolute quantification of free amino acids in human urine samples. We also applied this method to quantify the urine samples from a dietary intervention study.

\section{Materials and methods}

\section{Chemicals and reagents}

L-Phenylalanine (Phe), L-tryptophan (Trp), L-leucine (Leu), L-isoleucine (Ile), L-methionine (Met), L-valine (Val), 

mass chromatograms of the ions extracted for non-labelled and deuterated amino acids in a standard mix. Note For L-glycine- $\mathrm{d}_{5}$, we monitored Gly- $\mathrm{d}_{2}$ and for L-asparagine- $\mathrm{d}_{8}$, we monitored Asn- $\mathrm{d}_{3}$ as the remainders of the deuterium are exchangeable
Fig. 2 Typical UPLC accurate
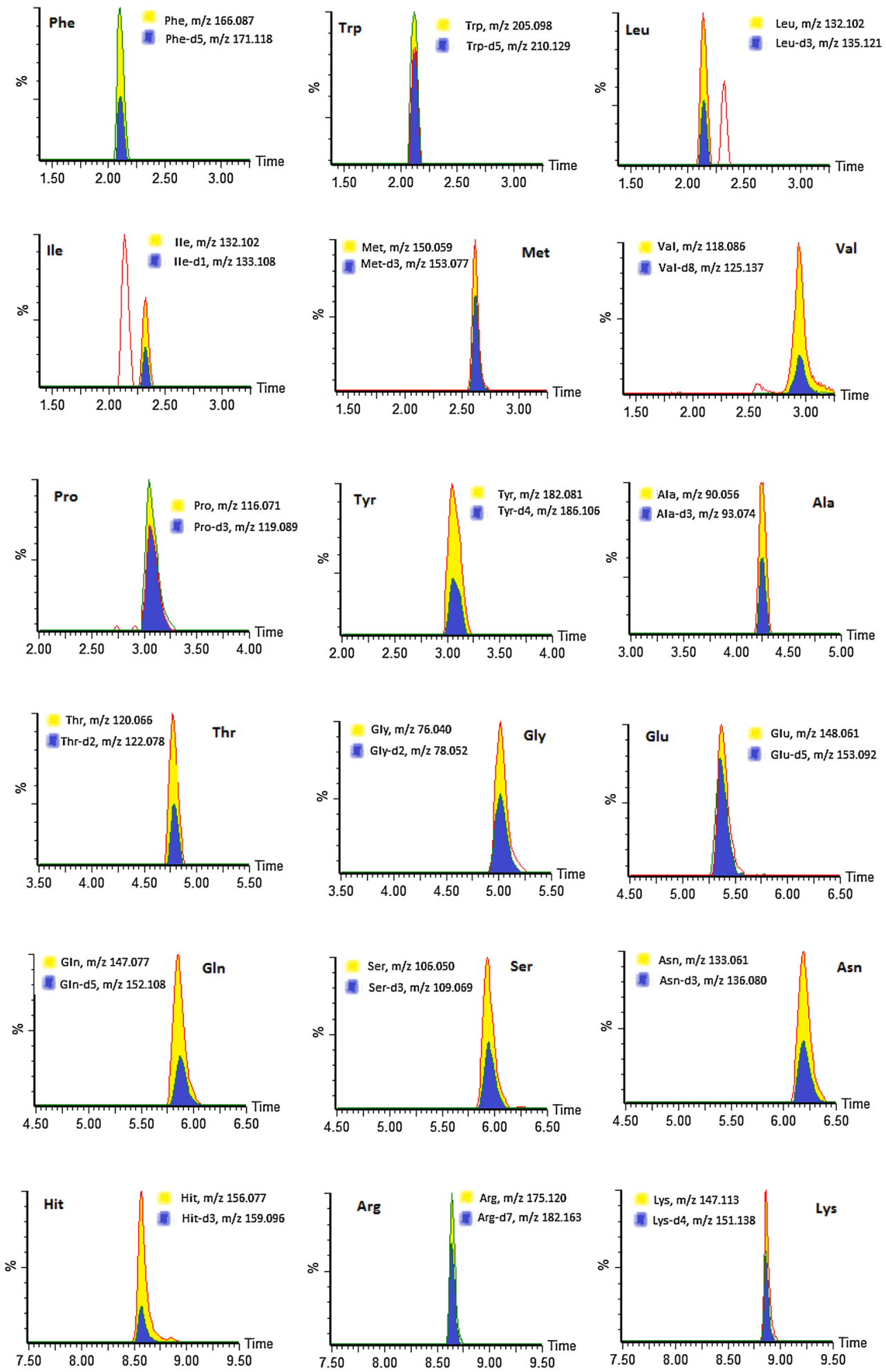

L-alanine (Ala), L-threonine (Thr), L-glycine (Gly), L-serine (Ser), L-asparagine (Asn), L-aspartic acid (Asp), L-cysteine (Cys), L-arginine (Arg), L-histidine (Hit), L-lysine (Lys) were purchased from Sigma-Aldrich (Gillingham, Dorset, UK). L-Proline (Pro), L-glutamic acid (Glu), L-glutamine (Gln) and L-tyrosine (Tyr) were purchased from
Fisher Scientific (Loughborough, UK). Their corresponding labelled amino acids, with the atom $\%$ deuteration shown in brackets, were purchased from Sigma-Aldrich for L-Phenyl-d5-alanine (Phe-d5, $98 \%$ ), L-tryptophan-indo-d ${ }_{5}$

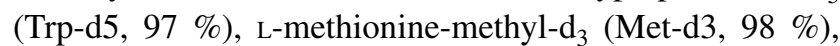
L-valine- $\mathrm{d}_{8}$ (Val-d8, $98 \%$ \%), L-proline-2,5,5- $\mathrm{d}_{3}$ (Pro-d3, 
Fig. 3 Typical UPLC accurate mass chromatograms of the ions extracted for non-labelled and deuterated amino acids in a urine sample
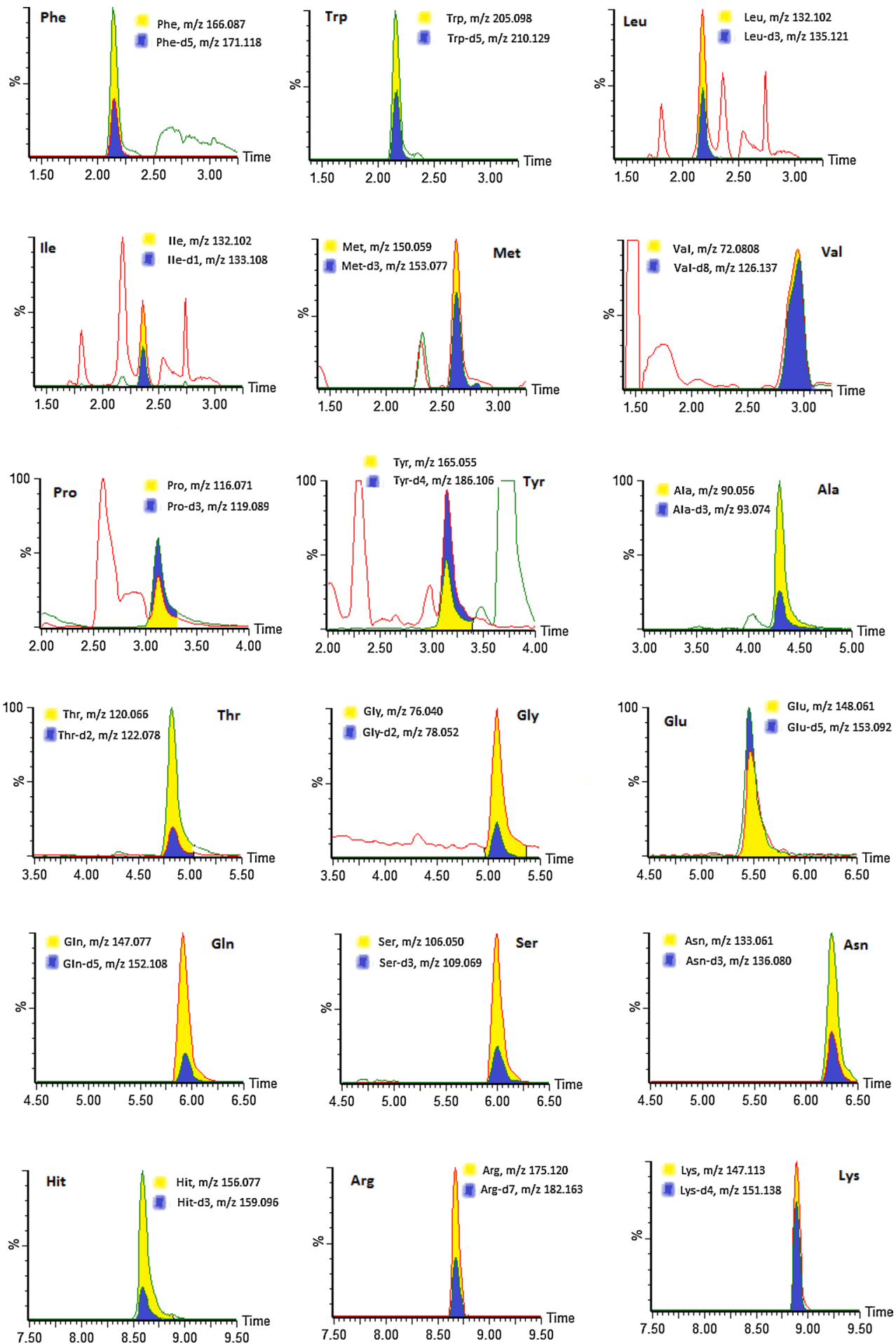

(Arg-d7, $98 \%$ ); and CND Isotopes (QMX, Thaxted, UK) for L-isoleucine-2- $\mathrm{d}_{1}$ (Ile-d1, $98.9 \%$ ), L-threonine-2,3- $\mathrm{d}_{2}$ (Thr-d2, $98.8 \%$ ), L-serine-2,3,3-d $\mathrm{d}_{3}$ (Ser-d3, $99.1 \%$ ) and L-glutamine-2,3,3,4,4-d $\mathrm{d}_{5}$ (Gln-d5, $\left.98.8 \%\right)$. All reference amino acids had a purity $>99 \%$. The HPLC grade acetonitrile, formic acid, and water were purchased from SigmaAldrich. Ammonium formate was purchased from Fisher 

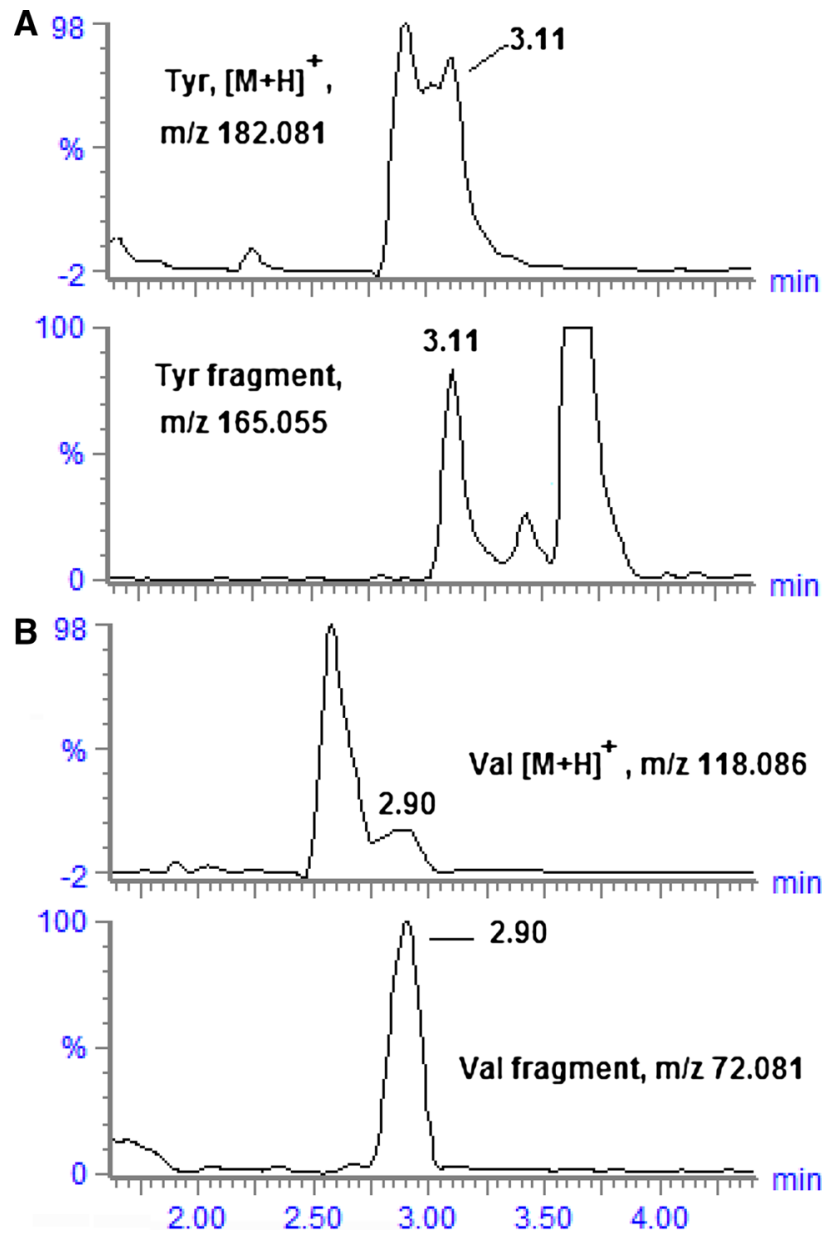

Fig. 4 Extracted ion chromatograms that show interference from other closely eluting compounds in the urine sample for molecular ions of Tyr (panel a) and Val (panel b), and their corresponding fragment ion that are free from interference

Scientific. All chemicals and reagents were of appropriate analytical grades.

\section{Instrumentation and experimental conditions}

The analyses of urine samples were performed on a Waters Synapt G2 UPLC-qTOF-MS (Waters Corporation, Wilmslow, UK) system consisting of a Waters binary solvent delivery system and an autosampler operating Masslynx acquisition software (Synapt, version 4.1 Waters, USA). The electrospray ionisation (ESI) used a capillary voltage of $0.8 \mathrm{kV}$ for positive mode; cone voltage $15 \mathrm{~V}$; source temperature $150{ }^{\circ} \mathrm{C}$; desolvation temperature $350{ }^{\circ} \mathrm{C}$; cone gas flow $50 \mathrm{~L} / \mathrm{h}$ and desolvation gas flow $800 \mathrm{~L} / \mathrm{h}$. The scan range was $\mathrm{m} / \mathrm{z} 50-600 \mathrm{Da}$ and the mass spectrometer resolution was 10,000 , enabling mass accuracy within $2 \mathrm{mDa}$. The Leu-enkephalin $(\mathrm{m} / \mathrm{z} 556.2771)$ was used as the lock mass solution for accurate mass calibration during long analytical sequences to counteract the potential effect of calibration drift during the long analytical run time.

Five microliters of each sample was injected onto a Waters ACQUITY UPLC BEH amide column $(1.7 \mu \mathrm{m}$, $2.1 \mathrm{~mm} \times 100 \mathrm{~mm})$ with a VanGuard HSS T3 $(1.8 \mu \mathrm{M})$ pre-column. The HILIC chromatographic condition was based on Guo et al. (2013) with modifications to the gradient, aiming to improve the sensitivity and specificity of analytes with longer retention time. The mobile phases consisted of an aqueous phase (A), containing water, $10 \mathrm{mM}$ ammonium formate, and $0.15 \%$ formic acid and an organic phase (B), containing acetonitrile, $1 \mathrm{mM}$ ammonium formate, and $0.15 \%$ formic acid. The flow rate was fixed at $0.4 \mathrm{~mL} / \mathrm{min}$ with a gradient elution that started at $15 \%$ of A and increased linearly to $20 \%$ in $6 \mathrm{~min} ; 20-45 \% \mathrm{~A}, 6-10 \mathrm{~min} ; 45-55 \% \mathrm{~A}$, $10-12.5 \mathrm{~min}$; and finally $55-95 \%$ in $0.1 \mathrm{~min}$. The LC flow was diverted to waste at $12.6 \mathrm{~min}$ and continued for $1.4 \mathrm{~min}$ of each run before the column was re-equilibrated in the initial condition for $2.9 \mathrm{~min}$, in an attempt to flush highly polar urine components off the column and away from the mass spectrometer source. The column was maintained at $35{ }^{\circ} \mathrm{C}$ and the samples were maintained at a temperature of $4{ }^{\circ} \mathrm{C}$ prior to injection. A strong (20\% acetonitrile: $80 \%$ water) and weak (80\% acetonitrile:20\%water) needle wash was performed between each injection.

\section{Preparation of standard solutions and calibration standards}

All stock solutions of labelled and non-labelled amino acids were prepared in water at 5 and $20 \mathrm{mM}$, respectively, except Tyr and Tyr-d4, both at $2 \mathrm{mM}$ due to its low solubility. These non-labelled stock solutions were used to prepare calibration standards in diluent and pooled urine sample. Calibration ranges were determined based on the concentrations observed in the pooled QC urine sample. A final seven-point calibration standards at $0.1,1.0,2.0,4.0,6.0,8.0$, and $12.0 \mu \mathrm{M}$ were prepared for Phe, Trp, Leu, Val and Thr. The calibration curves were at a factor of 0.1 for each of the above ranges for Arg and Glu; 0.2 for Met and Pro; 0.5 for Ile, Ser, Asn, and Lys; 1.5 for Gln; 2.5 for Tyr; 3 for Gly and Hit; and 5 for Ala. Cys and Asp were not added in the final calibration curve as neither was detected in the pooled QC sample. Moreover, Cys was found to be unstable and formed the dimer, cystine in the solution within 2 weeks and was hence not suitable for analysis of large-scale studies that involve long analytical runs whilst Asp gave a broad chromatographic peak.

A fixed amount of labelled amino acids were prepared at the same concentration of the third lowest point on the calibration curve for each amino acid, with a minimum 
Table 1 The matrix effects, coefficient of determination, limits of detection (LODs), lower limits of quantification (LLOQ) and upper limits of quantification (ULOQ) of each amino acid

\begin{tabular}{|c|c|c|c|c|c|c|c|}
\hline \multirow[t]{2}{*}{ Analyte } & \multicolumn{3}{|c|}{ Matrix effect } & \multirow[t]{2}{*}{ Coefficient of determination $\left(r^{2}\right)$} & \multirow[t]{2}{*}{ LOD (nM) } & \multirow[t]{2}{*}{ LLOQ $(\mu \mathrm{M})$} & \multirow[t]{2}{*}{ ULOQ $(\mu \mathrm{M})$} \\
\hline & Slope ratio & Ratio QCM & Ratio QCH & & & & \\
\hline Phe & 0.98 & 0.95 & 0.97 & 1.000 & 12.1 & 0.10 & 12.0 \\
\hline $\operatorname{Trp}$ & 0.99 & 0.96 & 0.99 & 1.000 & 4.4 & 0.10 & 12.0 \\
\hline Leu & 0.91 & 0.91 & 0.95 & 0.999 & 2.7 & 0.10 & 12.0 \\
\hline Ile & 0.94 & 0.91 & 0.92 & 0.995 & 1.3 & 0.05 & 6.0 \\
\hline Met & 0.97 & 0.94 & 0.95 & 0.997 & 0.7 & 0.02 & 2.4 \\
\hline Val & 0.97 & 0.96 & 0.97 & 0.999 & 44.1 & 0.10 & 12.0 \\
\hline Pro & 0.92 & 0.90 & 0.91 & 0.996 & 18.8 & 0.02 & 2.4 \\
\hline Tyr & 1.05 & 0.95 & 1.05 & 0.997 & 21.3 & 0.25 & 30.0 \\
\hline Ala* & 0.93 & 0.93 & 0.94 & 1.000 & 294.1 & 0.50 & 60.0 \\
\hline Thr & 0.99 & 1.10 & 1.08 & 0.999 & 12.3 & 0.10 & 12.0 \\
\hline Gly* & 0.95 & 0.93 & 0.91 & 0.999 & 145.2 & 0.30 & 36.0 \\
\hline Glu & 0.95 & 0.91 & 0.91 & 0.995 & 6.4 & 0.01 & 1.2 \\
\hline Gln & 1.00 & 1.03 & 1.04 & 1.000 & 23.9 & 0.15 & 18.0 \\
\hline Ser & 0.99 & 0.97 & 0.98 & 0.996 & 23.4 & 0.05 & 6.0 \\
\hline Asn & 1.03 & 0.98 & 0.99 & 0.998 & 20.8 & 0.05 & 6.0 \\
\hline Hit & 0.98 & 1.02 & 0.99 & 0.999 & 10.4 & 0.30 & 36.0 \\
\hline Arg & 1.03 & 1.00 & 1.10 & 0.999 & 5.9 & 0.01 & 1.2 \\
\hline Lys & 1.03 & 1.01 & 1.02 & 0.996 & 8.3 & 0.05 & 6.0 \\
\hline
\end{tabular}

LOD for Asp and Cys are 250 and $400 \mathrm{nM}$ (fresh solution), respectively. No other data were available as neither was detected in the biological matrix

$L L O Q$ lower limit of quantification. This corresponds to the lowest point in the calibration curve

$U L O Q$ upper limit of quantification. This corresponds to the highest point in the calibration curve

* Results based on four replicates after re-optimising the RF setting for low mass molecules

concentration of $1 \mu \mathrm{M}$ to ensure a good signal to noise ratio (S:N). All stock solutions were prepared and aliquoted and stored in glass vials at $-20{ }^{\circ} \mathrm{C}$ until analyses.

\section{Preparation of human urine and quality control samples}

All urine samples were deproteinized by the addition of acetonitrile $(100 \mu \mathrm{L}$ of urine: $1081.1 \mu \mathrm{L}$ of acetonitrile) and centrifugation at $1800 \mathrm{~g}$ for $10 \mathrm{~min}$. The supernatant (708.7 $\mu \mathrm{L}$ ) was added to $36 \mu \mathrm{L}$ of labelled stock solution and $155.3 \mu \mathrm{L}$ of water to give final solution of $900 \mu \mathrm{L}$ with composition of $75 \%$ acetonitrile: $25 \%$ aqueous and a final dilution of 15 times for the urine samples and 25 times for labelled stock solutions. A QC sample was prepared using an equal part of all 646 urine samples from a dietary intervention study (see amino acid quantitation in human urine samples later for the description of this study). A volume of $6 \mathrm{~mL}$ of the QC sample was used to prepare each of the QC-low (QCL), QC-medium (QCM) and QChigh $(\mathrm{QCH})$ samples, by spiking in a known concentration of each amino acid at 3, 30 and 75 times the lowest concentration on the calibration curve and they therefore represent a concentration in the low, medium and high range, respectively, of the calibration curve for each amino acid under investigation.

\section{Data analysis}

The chromatographic data were processed using QuanLynx (v 4.1, Waters, USA). Automatic generation of extracted ion chromatograms (EICs) was achieved by an $8 \mathrm{mDa}$ chromatogram mass window on the expected $\mathrm{m} / \mathrm{z}$ and mass resolution of 10,000 for both the analytes and their deuterated analogues. For amino acids with incomplete baseline separation of chromatographic peaks, the integration was manually adjusted to ensure the non-labelled standard and labelled internal standard peaks were processed in a uniform manner to ensure consistent results.

The calibration curves were constructed by calculating the chromatographic peak area ratio of the analyte and internal standard (IS) for each amino acid and at each concentration level. The ratio was calculated using (IS concentration $\div$ IS peak area) $\times$ analyte peak area. Linear regression analyses were performed using six replicates of the calibration curve data. The correlation coefficient $(r)$ was 
Table 2 Intra- and inter-day accuracy and precision

\begin{tabular}{|c|c|c|c|c|c|c|c|c|c|c|c|c|}
\hline \multirow[t]{3}{*}{ Analyte } & \multicolumn{6}{|c|}{ Intra-day reproducibility (over a single day) } & \multicolumn{6}{|c|}{ Inter-day reproducibility (over 4 weeks) } \\
\hline & \multicolumn{2}{|c|}{$\mathrm{QCL}(n=4)$} & \multicolumn{2}{|c|}{$\mathrm{QCM}(n=4)$} & \multicolumn{2}{|c|}{$\mathrm{QCH}(n=4)$} & \multicolumn{2}{|c|}{$\mathrm{QCL}(n=10)$} & \multicolumn{2}{|c|}{$\mathrm{QCM}(n=10)$} & \multicolumn{2}{|c|}{$\mathrm{QCH}(n=10)$} \\
\hline & $\begin{array}{l}\text { Accuracy } \\
\text { (bias, \%) }\end{array}$ & $\begin{array}{l}\text { Precision } \\
\text { (RSD, \%) }\end{array}$ & $\begin{array}{l}\text { Accuracy } \\
\text { (bias, \%) }\end{array}$ & $\begin{array}{l}\text { Precision } \\
\text { (RSD, \%) }\end{array}$ & $\begin{array}{l}\text { Accuracy } \\
\text { (bias, \%) }\end{array}$ & $\begin{array}{l}\text { Precision } \\
\text { (RSD, \%) }\end{array}$ & $\begin{array}{l}\text { Accuracy } \\
\text { (bias, \%) }\end{array}$ & $\begin{array}{l}\text { Precision } \\
(\text { RSD, \%) }\end{array}$ & $\begin{array}{l}\text { Accuracy } \\
\text { (bias, \%) }\end{array}$ & $\begin{array}{l}\text { Precision } \\
\text { (RSD, \%) }\end{array}$ & $\begin{array}{l}\text { Accuracy } \\
\text { (bias, \%) }\end{array}$ & $\begin{array}{l}\text { Precision } \\
\text { (RSD, \%) }\end{array}$ \\
\hline Phe & 10.0 & 11.6 & 1.5 & 2.0 & -0.7 & 1.2 & 4.7 & 8.1 & 1.9 & 2.1 & 1.2 & -0.8 \\
\hline $\operatorname{Trp}$ & 9.5 & 9.3 & 3.9 & 1.5 & 2.4 & 3.6 & 6.4 & 7.6 & 3.6 & 2.3 & 3.0 & 2.7 \\
\hline Leu & 1.7 & 2.6 & -0.3 & 0.4 & -3.5 & 1.9 & 0.9 & 2.5 & 2.2 & 4.8 & -1.2 & 4.2 \\
\hline Ile & 11.0 & 6.5 & 8.7 & 3.5 & 7.8 & 4.3 & 7.2 & 7.1 & 8.4 & 6.5 & 3.4 & 8.1 \\
\hline Met & 17.4 & 12.4 & 1.2 & 6.4 & 2.5 & 6.6 & 12.1 & 7.6 & 1.2 & 5.0 & -3.8 & 5.0 \\
\hline Val & 5.6 & 3.6 & 10.2 & 3.0 & 5.5 & 4.2 & 7.9 & 3.2 & 8.2 & 3.0 & 4.6 & 3.3 \\
\hline Pro & 7.5 & 9.1 & 6.9 & 5.3 & 7.7 & 1.3 & 7.0 & 8.1 & 0.4 & 8.8 & 1.9 & 6.6 \\
\hline Tyr & 4.0 & 6.5 & 6.9 & 7.2 & 2.1 & 2.6 & 5.7 & 10.3 & 2.8 & 7.3 & -4.7 & 7.9 \\
\hline Ala & 0.3 & 2.6 & 3.2 & 1.0 & 0.2 & 2.2 & -1.8 & 2.6 & 1.9 & 2.2 & 0.6 & 1.8 \\
\hline Thr & -7.7 & 12.8 & -3.2 & 4.4 & -1.8 & 4.5 & 0.5 & 10.5 & 1.9 & 5.1 & -2.0 & 6.0 \\
\hline Gly & 3.2 & 6.6 & 1.7 & 7.0 & -3.2 & 10.4 & 2.4 & 5.5 & 4.1 & 6.5 & -0.9 & 6.6 \\
\hline Glu & 11.3 & 5.3 & 0.0 & 9.7 & 1.1 & 14.0 & 13.0 & 8.8 & 5.4 & 9.0 & -0.3 & 9.3 \\
\hline Gln & 7.8 & 2.3 & 6.6 & 9.3 & -0.6 & 4.0 & 5.0 & 2.7 & 4.5 & 5.7 & 0.5 & 3.4 \\
\hline Ser & 12.4 & 6.1 & 6.4 & 8.1 & 6.8 & 11.7 & 11.0 & 9.8 & 5.4 & 6.8 & 1.9 & 8.0 \\
\hline Asn & 5.0 & 3.2 & 5.3 & 8.1 & 7.8 & 4.2 & 5.7 & 9.8 & 8.8 & 10.7 & 6.7 & 5.7 \\
\hline Hit & 8.6 & 4.4 & 3.4 & 2.5 & 0.8 & 2.7 & 6.4 & 3.7 & 2.7 & 2.9 & 0.8 & 2.2 \\
\hline Arg & 4.5 & 5.8 & 4.5 & 4.9 & 2.1 & 3.8 & 7.2 & 6.9 & 3.6 & 4.2 & -0.7 & 4.6 \\
\hline Lys & 7.0 & 6.2 & 5.3 & 2.6 & 1.5 & 1.5 & 4.8 & 7.6 & 2.0 & 3.9 & 0.1 & 2.0 \\
\hline
\end{tabular}

calculated for each amino acid and considered as acceptable when the coefficient of determination $r^{2} \geq 0.99$. The limit of detection (LOD) for each amino acid was determined using six replicates and was set at the chromatographic peak area compared to the blank sample with $\mathrm{S}: \mathrm{N}>3$. The lower limit of quantification (LLOQ) was set at the lowest concentration of the calibration curve.

The matrix effect was determined by comparing the slope of the calibration curves, prepared in biological matrix and in diluents, and the matrix effect was considered negligible for slope ratios in the range 0.9-1.1 (Jia et al. 2011; Chen et al. 2012; Guo et al. 2013). The slope ratio $=1$ implies no matrix effect of the mass spectrometer whilst ratio $>1$ indicates ionisation enhancement and $<1$ indicates suppression. The ratio of QCM and QCH was also measured against each calibration curve and similar acceptance criteria were applied. Carry-over was evaluated using both the highest point of the calibration curves and $\mathrm{QCH}$, followed by diluents in three replicates.

Intra- and inter-day accuracy and precision were evaluated using replicates of each QCL, QCM and QCH on the same day and over a 4-week period. Accuracy was determined by calculating the percentage of deviation of the measured amount by the actual added amount, \% accuracy $=$ [mean measured amount - mean nominal amount $\div$ mean nominal amount $] \times 100$; and precision was calculated by the relative standard deviation (RSD) for each amino acid, \% precision $=$ [standard deviation of mean measured amount $\div$ mean measured amount $] \times 100$. Precision and accuracy were considered acceptable when values were $<20 \%$ for QCL and $<15 \%$ for QCM and QCH for at least two-thirds of the replicates, based on the criteria outlined on the FDA guidelines (US Food and Drug Administration 2001). In addition, the stability of the amino acids in the urine samples was evaluated using a pooled QC urine sample under four different storage conditions: (1) freshly prepared; (2) short-term stability in $4{ }^{\circ} \mathrm{C}$ for $72 \mathrm{~h}$; (3) 4 weeks storage at $-80{ }^{\circ} \mathrm{C}$; and (4) one freeze-thaw cycle after storage at $-80^{\circ} \mathrm{C}$.

\section{Amino acid analysis by AccQ-Tag}

Seventeen urine samples were analysed using HPLC system with a pre-column fluorescent derivatization reagent, AccQ-Tag, and were prepared following manufacturer standard protocols (Cohen and Michaud 1993). Data for all free amino acids were compared using Bland-Altman analysis where the mean difference between the two methods (UPLC-qTOF-MS and Accq-Tag) was obtained (Bland and Altman 1986). The mean deviation (\%) of all 


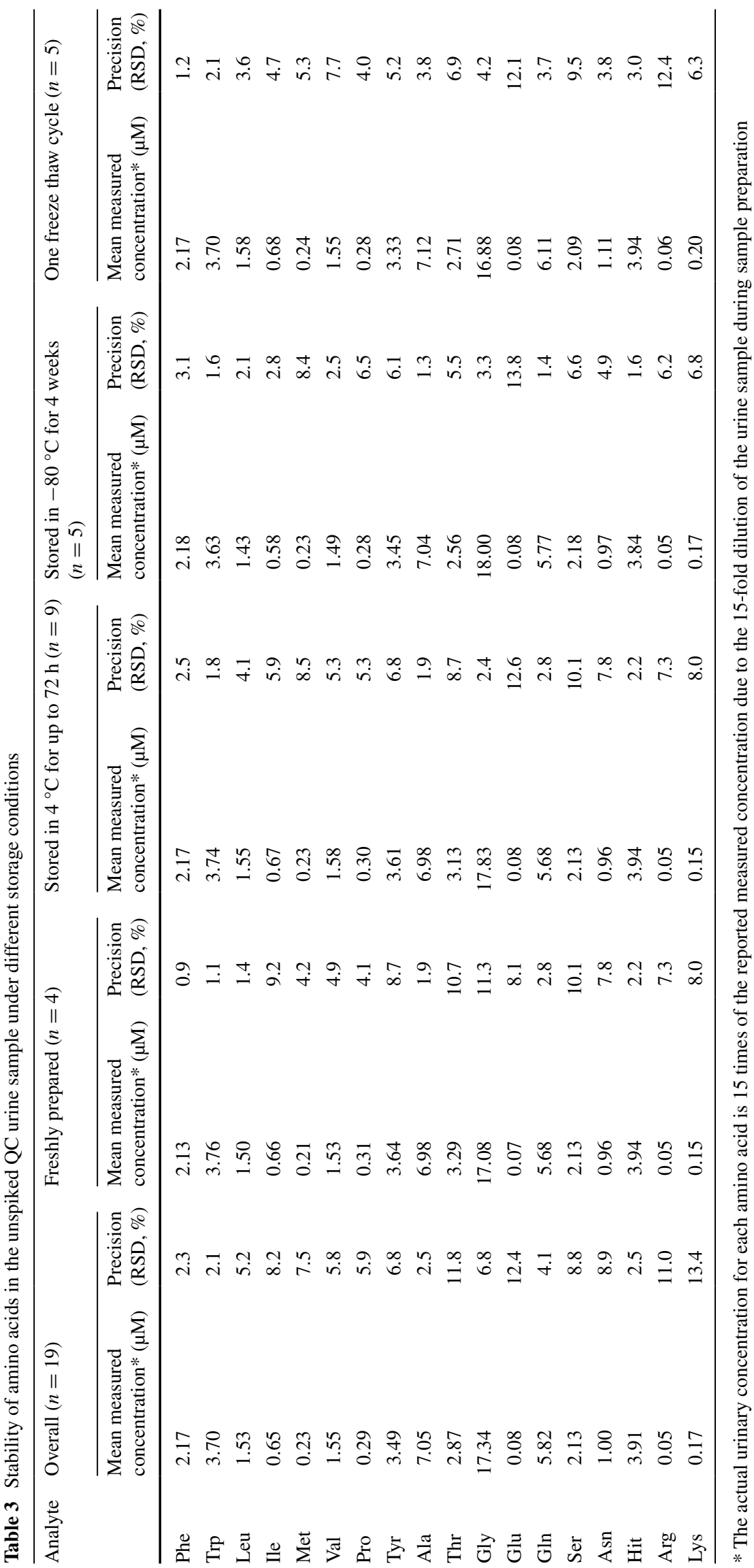


Table 4 Accuracy, precision and dynamic range for the quantification of amino acids in NIST certified standards (five replicates)

\begin{tabular}{|c|c|c|c|c|c|c|c|c|c|c|c|}
\hline \multirow[t]{2}{*}{ Analyte } & \multicolumn{4}{|c|}{ NIST standard $(0.8 \mu \mathrm{M})$} & \multicolumn{4}{|c|}{ NIST standard $(5 \mu \mathrm{M})$} & \multicolumn{3}{|c|}{ Dynamic range $^{c}$} \\
\hline & $\begin{array}{l}\text { Mean } \\
\text { measured con- } \\
\text { centration }(\mu \mathrm{M})\end{array}$ & SD & $\begin{array}{l}\text { Precision } \\
\text { (RSD, \%) }\end{array}$ & $\begin{array}{l}\text { Accuracy } \\
\text { (bias, \%) }\end{array}$ & $\begin{array}{l}\text { Mean } \\
\text { measured con- } \\
\text { centration }(\mu \mathrm{M})\end{array}$ & SD & $\begin{array}{l}\text { Precision } \\
(\mathrm{RSD}, \%)\end{array}$ & $\begin{array}{l}\text { Accuracy } \\
\text { (bias, \%) }\end{array}$ & $\begin{array}{l}\text { LLOQ } \\
(\mu \mathrm{M})\end{array}$ & $\begin{array}{l}\text { ULOQ } \\
(\mu \mathrm{M})\end{array}$ & $\begin{array}{l}\text { Coefficient of } \\
\text { determination } \\
\left(r^{2}\right)\end{array}$ \\
\hline Phe & 0.76 & 0.02 & 2.1 & -5.2 & 5.09 & 0.07 & 1.4 & 1.7 & 0.025 & 30.0 & 0.998 \\
\hline Leu & 0.72 & 0.02 & 3.2 & -9.6 & 5.04 & 0.13 & 2.6 & 0.7 & 0.0125 & 30.0 & 0.997 \\
\hline Ile & 0.76 & 0.02 & 2.2 & -4.6 & 4.77 & 0.21 & 4.4 & -4.6 & 0.0125 & 30.0 & 0.995 \\
\hline $\mathrm{Met}^{\mathrm{a}}$ & 0.77 & 0.02 & 2.2 & -4.0 & 5.01 & 0.16 & 3.3 & 0.2 & 0.00625 & 15.0 & 0.999 \\
\hline Val & 0.8 & 0.01 & 1.4 & -0.6 & 5.12 & 0.03 & 0.6 & 2.4 & 0.0025 & 6.0 & 0.993 \\
\hline Pro $^{a}$ & 0.77 & 0.01 & 0.8 & -3.6 & 5.11 & 0.12 & 2.3 & 2.2 & 0.1 & 30.0 & 0.996 \\
\hline Tyr & 0.77 & 0.03 & 3.9 & -3.7 & 4.84 & 0.13 & 2.6 & -3.2 & 0.02 & 6.0 & 0.998 \\
\hline $\mathrm{Ala}^{\mathrm{b}}$ & 0.77 & 0.02 & 2.7 & -3.5 & 4.61 & 0.06 & 1.2 & -7.9 & 0.0625 & 75.0 & 0.996 \\
\hline Thr & 0.78 & 0.01 & 1.3 & -2.4 & 4.95 & 0.15 & 3.1 & -1.0 & 0.5 & 150.0 & 0.997 \\
\hline Gly & 0.8 & 0.03 & 3.2 & -0.5 & 5.07 & 0.14 & 2.9 & 1.4 & 0.05 & 30.0 & 0.999 \\
\hline $\mathrm{Glu}^{\mathrm{b}}$ & 0.76 & 0.02 & 2.3 & -5.6 & 4.61 & 0.11 & 2.3 & -7.8 & 0.3 & 90.0 & 0.997 \\
\hline Ser & 0.81 & 0.03 & 3.1 & 1.4 & 4.95 & 0.10 & 2.1 & -1.0 & 0.01 & 3.0 & 0.997 \\
\hline Hit & 0.74 & 0.01 & 1.4 & -7.0 & 4.54 & 0.11 & 2.3 & -9.1 & 0.075 & 45.0 & 0.997 \\
\hline $\operatorname{Arg}^{\mathrm{a}}$ & 0.8 & 0.02 & 2.0 & -0.3 & 5.25 & 0.09 & 1.8 & 5.0 & 0.05 & 15.0 & 0.999 \\
\hline Lys & 0.78 & 0.02 & 2.8 & -1.9 & 4.91 & 0.10 & 2.1 & -1.8 & 0.05 & 15.0 & 0.999 \\
\hline
\end{tabular}

${ }^{a}$ The NIST Standard at $5 \mu \mathrm{M}$ is above the range of the standard calibration curve for Met, Pro, Glu and Arg. These compounds were also measured against NIST Standard at $0.025 \mu \mathrm{M}$. The mean, standard deviation, precision and accuracy were Met $(0.025 \mu \mathrm{M}, 0.0016,6.4$ and $1.7 \%)$, Pro $(0.025 \mu \mathrm{M}, 0.0014,5.7$ and $0.9 \%)$, Glu $(0.028 \mu \mathrm{M}, 0.0011,6.4$ and $12.3 \%)$ and $\operatorname{Arg}(0.027 \mu \mathrm{M}, 0.0033,12.1$ and $9.0 \%)$

${ }^{\mathrm{b}}$ A higher NIST Standard at $50 \mu \mathrm{M}$ was also measured for Ala due to its higher calibration range. The mean, standard deviation, precision and accuracy for Ala were $52 \mu \mathrm{M}, 0.4614,0.9$ and $4.0 \%$

c Standard calibration curves were created with a minimum concentration of $0.625 \mathrm{nM}$ and a maximum concentration of $150 \mu \mathrm{M}$. The LLOQ was taken as the concentration of the standard compound that gave a $\mathrm{S}: \mathrm{N}>5$ and the ULOQ was the highest concentration of the calibration curve

measurements and mean difference in both absolute measured value $(\mu \mathrm{M})$ and adjusted for urinary creatinine $(\mu \mathrm{M} /$ $\mathrm{mM}$ ) as measured by Jaffe method were obtained. The relative total technical error of measurement (TEM) as expressed in \% was calculated as $\frac{\sqrt{\frac{\sum d^{2}}{2 N}}}{\bar{x}} \times 100 \%$, where $d$ is the difference between measurements, $N$ is the number of measurements made on each occasion and $\bar{x}$ is the mean of all samples values (Ulijaszek and Kerr 1999).

\section{Amino acids quantitation in human urine samples}

Human urine samples were obtained from the OmniHeart Study. Details of the study design, aims and main outcomes of the study have been published (Appel et al. 2005; Carey et al. 2005; Furtado et al. 2008). Briefly, OmniHeart Study is a cross-over, three-period, randomised feeding trial where individuals were fed with three different healthy diets, each for 6 weeks. Urine samples were collected prior to the start of any dietary intervention and at the end of each 6 -week intervention ( $N=646$ urine samples). Urine samples were transferred on dry ice to our central laboratory in Chatham, Kent for storage until analysis. All participants provided formal written consent and ethics approval was obtained from Johns Hopkins University medical institutions and Brigham Women's Hospital.

We applied our method to quantify these 18 free amino acids using a random subset of human urine samples from the OmniHeart Study $(N=87)$ to evaluate the feasibility of this method on real biological matrix before applying the method on the remaining samples. This is important since our method had not previously been applied to human urine samples.

\section{Results and discussion}

\section{Method development and optimization}

This study aimed at the development and validation of a UPLC-qTOF-MS method using HILIC conditions for absolute quantitation of free amino acids in human urine samples. We assessed the optimal urine sample preparation 
process by adding fixed concentration of labelled compounds and diluting the pooled QC sample with water by a factor of $5,10,15,20,25,50,75$ and 100 times but maintaining the final composition of $75 \%$ acetonitrile: $25 \%$ aqueous. For most analytes, the results obtained were similar in the 15, 20 and 25 dilutions, with a maximum peak area for non-labelled compound in the 15-fold dilution, suggesting a degree of ion suppression at lower dilutions. Some compounds (Met, Val, Gly, Glu, Ser, Asn, Lys) were not detected in the QC pooled samples at dilutions greater than 15 , suggesting that the absolute concentrations in these dilutions were approaching the LOD. All urine samples were, therefore, subsequently prepared using a 15 -fold dilution.

We found the quadrupole RF settings were not optimal and this restricted the passage of low molecular mass ions $(<100)$. We improved it by optimising the RF setting of the qTOF instrument, adjusting the RF offset settings to: source, $100 \mathrm{~V}$; trap $140 \mathrm{~V}$; IMS $50 \mathrm{~V}$; and transfer $100 \mathrm{~V}$. This resulted in increases in signal for Gly and Ala of approximately 50- and 10-fold, respectively (Fig. 1). The signal for other amino acids was not affected.

Typical accurate mass chromatograms from a standard mix solution are shown in Fig. 2. All amino acids show satisfactory peak shape and minimal peak overlapping. The accurate mass chromatogram of urine samples is clearly more complex than the standard mix solution (Fig. 3). For all amino acids except Val and Tyr, we used the accurate mass for protonated molecular ion, $[\mathrm{M}+\mathrm{H}]^{+}$and the retention time to correctly identify and quantify the analytes. For Val and Tyr, the $[\mathrm{M}+\mathrm{H}]^{+}$ions show closely co-eluting compounds in the urine sample which prevent accurate quantification of $\mathrm{Val}$ and Tyr using $[\mathrm{M}+\mathrm{H}]^{+}$. However, we were able to use fragment ions at $\mathrm{m} / \mathrm{z} 72.081$ $\left(\left[\mathrm{M}+\mathrm{H}-\mathrm{HCO}_{2} \mathrm{H}\right]^{+}\right)$and $165.056\left(\left[\mathrm{M}+\mathrm{H}^{-N_{3}}\right]^{+}\right)$, respectively, to quantify the concentration of these two amino acids (Fig. 4). In both cases, the fragment ions are considerably less intense than the $[\mathrm{M}+\mathrm{H}]^{+}$ions, at approximately 4 and 15 times for Val and Tyr, respectively. This reduces the potential sensitivity and specificity of the method for these two compounds. Nevertheless, the combination of the detection of the correct fragment ion at the correct retention time provided adequate confidence on the use of the fragment ions. We recognise that the use of fragment ions is less satisfactory than the use of $[\mathrm{M}+\mathrm{H}]^{+}$ions but this was not possible due to interference from the urine samples.

\section{Selectivity, linearity, matrix effects and reproducibility of UPLC-qTOF-MS approach}

Table 1 shows the results of the matrix effects, linearity, LOD, LLOQ and upper LOQ (ULOQ) of the method.
The slope ratios of the calibration curves, QCM and QCH for all 18 analytes were between 0.9 and 1.1, indicating minimum matrix effects based on a 15 -fold dilution. Since both types of calibration curves generated similar results, we have subsequently decided to prepare all calibration curves using diluent. The effects of carry-over were evaluated using the highest point of the calibration curve and QCH. No peak corresponding to labelled analytes was detected in the blank diluent (data not shown). The linearity, $r^{2}$, was $\geq 0.995$ for all amino acids and the dynamic range of the method, based on the calibration curve, was typically at two orders of magnitude (120-fold of the LLOQ). The intra- and inter-day accuracy and precision based on the QCL, QCM and $\mathrm{QCH}$ are shown in Table 2. The intra-day accuracy and precision were determined using four replicates of QCL, $\mathrm{QCM}$ and $\mathrm{QCH}$ in a single run. The inter-day analysis was performed using ten replicates over 4 weeks. We found our method fully complied with the FDA guidelines and with accuracy and precision of typically $<15 \%$ for QCL, QCM and QCH. The stability of the amino acids in urine samples was evaluated under four different conditions (Table 3). The urine samples remained stable for up to $72 \mathrm{~h}$ at fridge temperature $\left(4{ }^{\circ} \mathrm{C}\right)$; for 4 weeks when stored at $-80^{\circ} \mathrm{C}$; and when subjected to one freeze thaw cycle. These results were comparable to those from freshly prepared urine samples. The precision of all 19 replicates based on pooled QC samples for all four different conditions was generally $<15 \%$ for all amino acids. These results together with those from Table 2 thus show good reproducibility and providing confidence in our method.

We found our method generally offered similar or better sensitivity than that obtained by other triple quadrupole methods using MRM detection and HILIC chromatography. The use of MRM enables the selection of single precursor and product ion for each compound of interest and therefore provides high specificity and selectivity for the quantification of each analyte. Specificity in our UPLC-qTOF-MS method is provided by the generation of accurate mass chromatograms and generally gave considerably lower LODs, between 20 and 50 times, for Arg, Glu, Lys, Asn, Hit, Ser and Thr but lower sensitivity for Pro and Ala (Guo et al. 2013; Yao et al. 2013). Our method also provided lower detection limits than other reported methods using time of flight mass analysers (Paglia et al. 2012). However, some recent advances in MS have applied the orbitrap mass spectrometer, operating in full scan mode (Nemkov et al. 2015), resulting in considerably better sensitivity. Domingues et al. applied triple quadrupole MRM method showing better sensitivity than our method, with LLOQ in the values of tens of nanomoles (Domingues et al. 2015). Others make use of 
Table 5 Application of UPLC-qTOF-MS for the analysis of 87 human urine samples acquired in one batch

\begin{tabular}{|c|c|c|c|c|c|c|c|c|c|}
\hline \multirow[t]{2}{*}{ Analyte } & \multicolumn{3}{|l|}{ QCL $(n=6)$} & \multicolumn{3}{|l|}{$\mathrm{QCM}(n=6)$} & \multicolumn{3}{|l|}{$\mathrm{QCH}(n=6)$} \\
\hline & $\begin{array}{l}\text { Mean measured } \\
\text { concentration* } \\
(\mu \mathrm{M})\end{array}$ & $\begin{array}{l}\text { Accuracy } \\
\text { (bias, \%) }\end{array}$ & $\begin{array}{l}\text { Precision } \\
(\text { RSD }, \%)\end{array}$ & $\begin{array}{l}\text { Mean measured } \\
\text { concentration* }(\mu \mathrm{M})\end{array}$ & $\begin{array}{l}\text { Accuracy } \\
\text { (bias, \%) }\end{array}$ & $\begin{array}{l}\text { Precision } \\
\text { (RSD, \%) }\end{array}$ & $\begin{array}{l}\text { Mean measured } \\
\text { concentration* }(\mu \mathrm{M})\end{array}$ & $\begin{array}{l}\text { Accuracy } \\
\text { (bias, \%) }\end{array}$ & $\begin{array}{l}\text { Precision } \\
\text { (RSD, \%) }\end{array}$ \\
\hline Phe & 2.52 & 1.7 & 3.9 & 5.29 & 2.3 & 2.0 & 9.60 & -0.8 & 1.3 \\
\hline Trp & 4.11 & 3.8 & 4.3 & 6.87 & 3.1 & 2.4 & 11.53 & 3.3 & 2.2 \\
\hline Leu & 1.82 & 0.5 & 2.6 & 4.68 & 3.8 & 5.6 & 9.04 & 0.3 & 4.7 \\
\hline Ile & 0.81 & 3.8 & 2.9 & 2.30 & 7.8 & 8.1 & 4.40 & 0.3 & 9.0 \\
\hline Met & 0.32 & 10.4 & 3.7 & 0.84 & 1.6 & 4.1 & 1.65 & -4.5 & 4.2 \\
\hline Val & 1.99 & 9.3 & 2.5 & 4.82 & 6.8 & 2.4 & 9.38 & 4.1 & 2.8 \\
\hline Pro & 0.36 & 5.0 & 3.7 & 0.84 & -4.7 & 4.2 & 1.74 & -2.4 & 3.8 \\
\hline Tyr & 4.38 & 5.6 & 12.7 & 10.85 & -0.4 & 4.6 & 20.07 & -9.4 & 5.4 \\
\hline Ala & 8.33 & -2.9 & 2.5 & 22.35 & 1.2 & 2.7 & 45.00 & 0.9 & 1.7 \\
\hline Thr & 3.02 & 2.9 & 6.9 & 5.83 & 3.5 & 5.1 & 9.79 & -3.3 & 4.8 \\
\hline Gly & 18.60 & 1.4 & 4.4 & 27.88 & 5.5 & 6.7 & 40.15 & 0.5 & 3.2 \\
\hline Glu & 0.13 & 16.1 & 7.9 & 0.41 & 9.4 & 6.1 & 0.82 & -1.0 & 6.2 \\
\hline Gln & 6.66 & 4.3 & 3.0 & 10.83 & 3.8 & 2.7 & 17.45 & 1.5 & 1.9 \\
\hline Ser & 2.54 & 11.1 & 11.9 & 3.83 & 5.3 & 6.5 & 5.83 & -0.9 & 3.3 \\
\hline Asn & 1.29 & 7.9 & 9.6 & 2.85 & 12.0 & 10.6 & 5.10 & 6.4 & 6.8 \\
\hline Hit & 5.02 & 4.7 & 2.1 & 13.18 & 2.3 & 3.2 & 26.62 & 0.9 & 2.1 \\
\hline Arg & 0.09 & 9.6 & 5.8 & 0.36 & 3.1 & 4.1 & 0.78 & -2.5 & 4.6 \\
\hline Lys & 0.35 & 4.8 & 8.5 & 1.69 & 0.1 & 4.1 & 3.91 & -0.8 & 2.1 \\
\hline
\end{tabular}

* The actual urinary concentration for each amino acid is 15 times of the reported measured concentration due to the 15-fold dilution of the urine sample during sample preparation

derivatization agents (Armenta et al. 2009; Salazar et al. 2012) and ion-pairing agents ( $\mathrm{Gu}$ et al. 2007; Le et al. 2014) for targeted analysis of polar metabolites including amino acids. Although these methods show better sensitivity than our method, the need of derivatization could introduce potential errors. Moreover, based on our previous experience, our initial assessment using an ionpairing agent, perfluorocarboxylic acid, together with a reverse-phase UPLC-MS method for quantification of free amino acids has generated numerous challenges. We found the accumulation of perfluorocarboxylic acid in the instrument contaminated both the positive and negative ion electrospray which affects the sensitivity of the MS for this analysis and for analyses performed by other users on the same instrument. The accumulation of perfluorooctanoic acid in the column also affected the properties of column and led to instability of retention time for several amino acids (data not shown). These limit the application of the method and are particularly not suitable for use in our institution where the instrument is used by other users for different types of analyses on a daily basis.
As a consequence, we applied a HILIC method that does not require any derivatization or ion-pairing agents. Our method using the qTOF at high resolution enables accurate mass scanning across $\mathrm{m} / \mathrm{z}$ 50-600. This enables targeted analysis, of all 18 free amino acids by spiking in deuterated internal standards, and untargeted analysis of other compounds present in the analytical samples in the same analytical run. We considered that the latter feature offers a significant advantage over some of the existing methods as these data may be further analysed to extract additional useful information. The data on untargeted analysis are beyond the scope of this paper and therefore will not be discussed further.

The throughput of our method is good, $18 \mathrm{~min}$ per sample including column re-equilibration time. Our throughput may not be as high compared to some of the methods discussed here, typically with a total acquisition of $<10$ min (Buiarelli et al. 2013; Nemkov et al. 2015), whilst Nemkov et al. by far is the quickest method with a 3-min acquisition time (Nemkov et al. 2015). 
Table 6 Application of UPLC-qTOF-MS for the analysis of 646 human urine samples, analysed over a total of 5 batches

\begin{tabular}{|c|c|c|c|c|c|c|c|c|c|}
\hline \multirow[t]{2}{*}{ Analyte } & \multicolumn{3}{|l|}{ QCL $(n=45)$} & \multicolumn{3}{|l|}{$\mathrm{QCM}(n=45)$} & \multicolumn{3}{|l|}{$\mathrm{QCH}(n=45)$} \\
\hline & $\begin{array}{l}\text { Mean measured } \\
\text { concentration* } \\
(\mu \mathrm{M})\end{array}$ & $\begin{array}{l}\text { Accuracy } \\
\text { (bias, \%) }\end{array}$ & $\begin{array}{l}\text { Precision } \\
\text { (RSD, \%) }\end{array}$ & $\begin{array}{l}\text { Mean measured } \\
\text { concentration* } \\
(\mu \mathrm{M})\end{array}$ & $\begin{array}{l}\text { Accuracy } \\
\text { (bias, \%) }\end{array}$ & $\begin{array}{l}\text { Precision } \\
\text { (RSD, \%) }\end{array}$ & $\begin{array}{l}\text { Mean measured } \\
\text { concentration* } \\
(\mu \mathrm{M})\end{array}$ & $\begin{array}{l}\text { Accuracy } \\
\text { (bias, \%) }\end{array}$ & $\begin{array}{l}\text { Precision } \\
\text { (RSD, \%) }\end{array}$ \\
\hline Phe & 2.56 & 3.7 & 3.3 & 5.32 & 3.0 & 2.0 & 9.69 & 0.2 & 1.7 \\
\hline Trp & 4.25 & 3.0 & 4.0 & 7.05 & 3.2 & 2.9 & 11.57 & 2.1 & 2.5 \\
\hline Leu & 1.84 & 0.8 & 3.6 & 4.66 & 3.0 & 3.5 & 9.17 & 1.5 & 3.1 \\
\hline Ile & 0.82 & 2.3 & 5.5 & 2.32 & 7.5 & 5.0 & 4.44 & 0.8 & 4.4 \\
\hline Met & 0.32 & 5.0 & 6.8 & 0.84 & -0.3 & 4.4 & 1.68 & -3.8 & 3.5 \\
\hline Val & 2.05 & 7.4 & 7.2 & 4.83 & 4.7 & 4.0 & 9.42 & 3.4 & 2.4 \\
\hline Pro & 0.38 & 3.1 & 6.1 & 0.90 & -0.6 & 8.0 & 1.77 & -2.0 & 5.1 \\
\hline Tyr & 4.55 & 3.4 & 7.2 & 11.16 & 0.1 & 5.5 & 21.58 & -3.6 & 4.5 \\
\hline Ala & 8.54 & -1.2 & 2.6 & 22.38 & 1.1 & 2.9 & 45.10 & 1.0 & 2.6 \\
\hline Thr & 3.05 & 0.7 & 4.4 & 5.86 & 2.2 & 3.2 & 10.07 & -1.6 & 3.1 \\
\hline Gly & 18.81 & 2.8 & 2.7 & 27.62 & 4.6 & 3.7 & 39.82 & -0.2 & 3.1 \\
\hline Glu & 0.12 & 9.6 & 8.8 & 0.41 & 7.5 & 5.5 & 0.84 & 1.3 & 4.9 \\
\hline Gln & 6.53 & 4.2 & 2.5 & 10.72 & 3.9 & 2.5 & 17.33 & 1.6 & 2.6 \\
\hline Ser & 2.36 & 4.7 & 6.4 & 3.74 & 3.8 & 6.1 & 5.76 & -1.5 & 4.2 \\
\hline Asn & 1.21 & 4.0 & 6.5 & 2.63 & 4.4 & 7.1 & 4.90 & 2.9 & 4.8 \\
\hline Hit & 4.98 & 5.0 & 2.3 & 13.19 & 2.7 & 2.5 & 26.42 & 0.3 & 2.4 \\
\hline Arg & 0.09 & 8.9 & 5.3 & 0.36 & 1.6 & 3.8 & 0.79 & -1.0 & 3.3 \\
\hline Lys & 0.34 & 3.5 & 6.5 & 1.66 & -0.9 & 4.1 & 3.85 & -1.8 & 4.2 \\
\hline
\end{tabular}

* The actual urinary concentration for each amino acid is 15 times of the reported measured concentration due to the 15-fold dilution of the urine sample during sample preparation

\section{Comparison of amino acid analysis with AccQ-Tag}

The data obtained by the AccQ-Tag method were unsatisfactory for most amino acids. Throughout the chromatogram, large numbers of compounds in the urine were found to co-elute with the free amino acids. In addition, co-elution amongst free amino acids was also observed, such as Ser, Asn and Gln. Manual processing on all the data had enabled confident quantification of four amino acids, namely Phe, Trp, Leu and Ile. We subsequently calculated the TEM for these four amino acids and found the TEM was typically $<26 \%$ (Ile $15.7 \%$, Phe $17.2 \%$, Leu $17.7 \%$ and Trp $25.6 \%$ ).

Bland-Altman plots that assess the agreement between two different measurement techniques were plotted for Phe, Try, Leu and Ile using both the absolute measured value $(\mu \mathrm{M})$ and adjusted for urinary creatinine $(\mu \mathrm{M} / \mathrm{mM})$. The mean difference between two measurements and limits of agreement within \pm 1.96 standard deviation (SD) of the differences are included as references. As the results were similar for both the mean absolute measured values and the adjusted for urinary creatinine values, we only presented the results based on the adjusted for urinary creatinine (Fig. 5). In general, we found all four amino acids showed good agreement between the two methods. The mean difference to the mean concentration for all measurements between the two methods was the lowest for Ile $(2.9 \%)$, followed by Phe (11.4\%), Trp (12.1\%) and the highest for Leu $(16.1 \%)$. Moreover, individual measurement differences of the four amino acids scatter randomly with no apparent systematic error being detected. We also plotted the Bland-Altman plots for the remaining 14 amino acids and found these amino acids showed lower concentration values for UPLC-qTOF-MS method. We found the mean differences were proportionately more negative with higher concentration of the analyte indicating some systematic errors. This is in compliance with our observations where co-elution was observed in AccQ-Tag method. An exemplar of this is shown using Asn, Fig. 5e.

As the majority of the free amino acids were not validated using the AccQ-Tag method, we then validated our method using a NIST certified amino acids standard containing 17 amino acids at $2.5 \mathrm{mM}$ each. This NIST standard contains all the amino acid of our interest except Trp, Gln and Asn. However, as the Bland-Altman plots show good agreement between AccQ-Tag and UPLC-qTOF-MS for Trp, we deemed the results of our UPLC-qTOF-MS were acceptable for Trp. However, we were unable to further validate the results for Gln and Asn. The remaining 15 amino acids (Ala, Arg, 

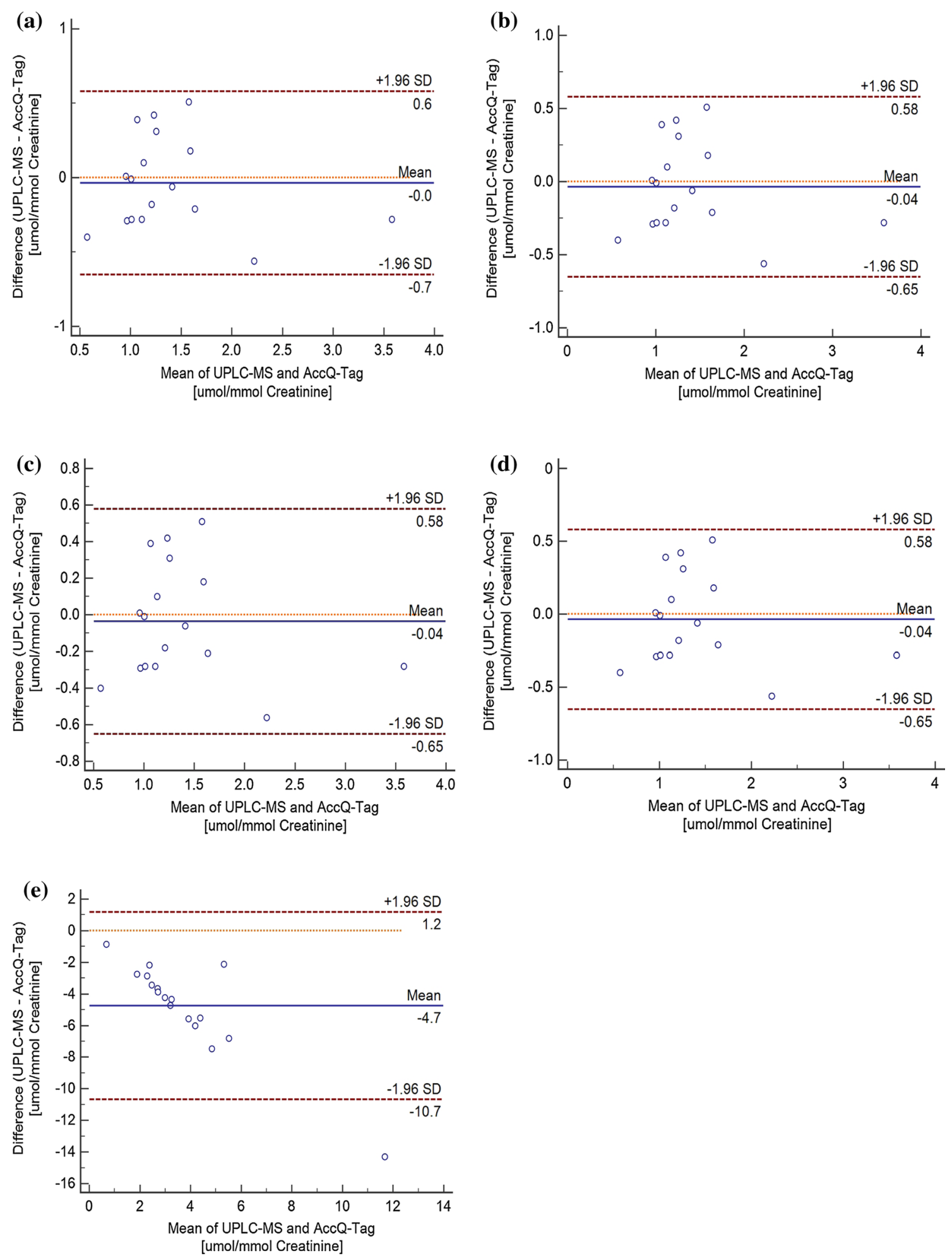

Fig. 5 Bland-Altman plots for amino acids showing agreement between UPLC-MS and AccQ-Tag methods for a Phe, b Trp, $\mathbf{c}$ Ile, $\mathbf{d}$ Leu, and e Asn

Glu, Gly, Hit, Ile, Leu, Lys, Met, Phe, Pro, Ser, Thr, Tyr and Val) were analysed by UPLC-qTOF-MS method after serial dilution with water to give concentrations of 0.8 and $5 \mu \mathrm{M}$.
These concentrations were chosen to allow the majority of amino acids to have at least two concentration points that fall within our standard calibration curve for each compound. In 
addition, we also extended the calibration curves to 14-point calibration curve for each amino acid to accommodate the compounds that were above or below the initial seven-point calibration curve. Each NIST standard $(0.8$ and $5 \mu \mathrm{M})$ was analysed in replicates of five and the results are presented in Table 4 . The majority of the amino acids show good accuracy and precision (generally $<5 \%$ ), again were well within the required FDA guidelines for developing an analytical method for the analysis of biofluids. Based on these results, we found the dynamic range of our calibration curve could potentially be extended considerably up to three orders magnitude (up to 2400 -fold) for six of the amino acids. The dynamic range for Tyr, Pro, Thr, Glu, Ser, Lys and Arg was extended to 300-fold whilst for Gly and Hit, they were extended to 600 -fold. The linearity for this extended dynamic range remains good with $r^{2} \geq 0.993$ (Table 4). This extended dynamic range is similar to that reported for triple quadrupole methods of $2-3$ orders of magnitude (Guo et al. 2013).

\section{Clinical application}

Having validated our UPLC-qTOF-MS method using the NIST standard and to show utility of this method in real samples, we analysed 87 urine samples randomly selected from the OmniHeart study. We were able to detect and quantify all 18 free amino acids in all urine samples. The levels of concentration detected were generally within the ranges of the calibration curve used here in this paper. In our experimental design, we included the analysis of a QC pooled sample in every 12th sample and included three replicates of QCL, QCM and QCH as well as a seven-point calibration standards. Using this design, we were able to complete the analysis of 87 samples within 2 days. This is quicker than existing methods such as the AccQ-Tag and ninhydrin methods where these methods typically required $2-3 \mathrm{~h}$ analysis time per sample. We found the accuracy and precision of the QCL, QCM and QCH fulfilled current FDA requirements (Table 5). We then applied this method to quantify the remaining 559 samples. These were analysed over 4 batches, with some batches containing up to 192 samples. Each batch was analysed without cleaning the instrument. A total of $45 \mathrm{QCL}, \mathrm{QCM}$ and QCH samples were acquired. We use a $25 \mathrm{mDa}$ chromatogram mass window to extract the EICs to mitigate any effects of mass calibration drift in the instrument over long (up to $90 \mathrm{~h}$ for some batches) chromatographic runs. These QC samples were used to evaluate the inter-batch precision and accuracy of our method. We found the inter-batch accuracy and precision was typically $<10 \%$ for QCL and QCM and $<5 \%$ for QCH (Table 6).

\section{Conclusion}

A HILIC-based chromatographic method was adapted to a UPLC-qTOF platform for simultaneous quantification of 18 free amino acids in human urine samples. The UPLCqTOF-MS method involves a facile sample preparation step which involves dilution with acetonitrile without the need of any derivatization. The method has been successfully applied for the analysis of human urine samples obtained from human volunteers with good accuracy and precision that passed all the FDA requirements. This demonstrates our approach a potential valuable tool to provide high-quality targeted analysis for the characterization of free amino acids in the urine samples. Moreover, the UPLC-qTOF-MS method also offers an added advantage whereby additional untargeted data collected during the analysis may be further analysed to extract useful information.

Acknowledgments R.L. Loo acknowledges support from the MRC New Investigator Grant Award (G1002151) and X. Zou is a postdoc and R. Joyce a part-time technician working on the grant. We also thank C Lapthorne for technical advice in instrument set-up and operation; and $\mathrm{J}$ Everett for providing constructive feedback on the manuscript.

\section{Compliance with ethical standards}

Conflict of interest The authors have declared that no competing interest exists.

Open Access This article is distributed under the terms of the Creative Commons Attribution 4.0 International License (http://creativecommons.org/licenses/by/4.0/), which permits unrestricted use, distribution, and reproduction in any medium, provided you give appropriate credit to the original author(s) and the source, provide a link to the Creative Commons license, and indicate if changes were made.

\section{References}

Appel LJ, Sacks FM, Carey VJ et al (2005) Effects of protein, monounsaturated fat, and carbohydrate intake on blood pressure and serum lipids: results of the omniheart randomized trial. JAMA 294(19):2455-2464. doi:10.1001/jama.294.19.2455

Armenta JM, Cortes DF, Pisciotta JM, Shuman JL, Blakeslee K, Rasoloson D, Ogunbiyi O, Sullivan DJ, Shulaev V (2009) Sensitive and rapid method for amino acid quantitation in malaria biological samples using AccQ•Tag ultra performance liquid chromatography-electrospray ionization-MS/MS with multiple reaction monitoring. Anal Chem 82(2):548-558. doi:10.1021/ ac901790q

Armstrong M, Jonscher K, Reisdorph NA (2007) Analysis of 25 underivatized amino acids in human plasma using ion-pairing reversed-phase liquid chromatography/time-of-flight mass spectrometry. Rapid Commun Mass Spectrom 21(16):2717-2726. doi:10.1002/rcm.3124 
Batch BC, Hyland K, Svetkey LP (2014) Branch chain amino acids: biomarkers of health and disease. Curr Opin Clin Nutr Metab Care 17(1):86-89. doi:10.1097/MCO.0000000000000010

Bland JM, Altman DG (1986) Statistical methods for assessing agreement between two methods of clinical measurement. Lancet 1(8476):307-310. doi:S0140-6736(86)90837-8 [pii]

Buiarelli F, Gallo V, Di Filippo P, Pomata D, Riccardi C (2013) Development of a method for the analysis of underivatized amino acids by liquid chromatography/tandem mass spectrometry: application on standard reference material 1649a (urban dust). Talanta 115:966-972. doi:10.1016/j.talanta.2013.07.009

Carey VJ, Bishop L, Charleston J, Conlin P, Erlinger T, Laranjo N, McCarron P, Miller E, Rosner B, Swain J, Sacks FM, Appel LJ (2005) Rationale and design of the optimal macro-nutrient intake heart trial to prevent heart disease (OMNI-Heart). Clin Trials 2(6):529-537. doi:10.1191/1740774505cn123oa

Chen L, Song F, Liu Z, Zheng Z, Xing J, Liu S (2012) Multi-residue method for fast determination of pesticide residues in plants used in traditional chinese medicine by ultra-high-performance liquid chromatography coupled to tandem mass spectrometry. J Chromatogr A 1225:132-140. doi:10.1016/j.chroma.2011.12.071

Chen X, Gao D, Liu F, Gao X, Wang S, Zhao Y, Liu H, Jiang Y (2014) A novel quantification method for analysis of twenty natural amino acids in human serum based on N-phosphorylation labeling using reversed-phase liquid chromatography-tandem mass spectrometry. Anal Chim Acta 836:61-71. doi:10.1016/j. aca.2014.05.053

Cohen SA, Michaud DP (1993) Synthesis of a fluorescent derivatizing reagent, 6-aminoquinolyl-N-hydroxysuccinimidyl carbamate, and its application for the analysis of hydrolysate amino acids via high-performance liquid chromatography. Anal Biochem 211(2):279-287. doi:10.1006/abio.1993.1270

Dietzen DJ, Weindel AL, Carayannopoulos MO, Landt M, Normansell ET, Reimschisel TE, Smith CH (2008) Rapid comprehensive amino acid analysis by liquid chromatography/tandem mass spectrometry: comparison to cation exchange with postcolumn ninhydrin detection. Rapid Commun Mass Spectrom 22(22):3481-3488. doi:10.1002/rcm.3754

Domingues DS, Crevelin EJ, de Moraes LAB, Cecilio Hallak JE, de Souza Crippa JA, Costa Queiroz ME (2015) Simultaneous determination of amino acids and neurotransmitters in plasma samples from schizophrenic patients by hydrophilic interaction liquid chromatography with tandem mass spectrometry. J Sep Sci 38(5):780-787. doi:10.1002/jssc.201400943

Fernández-Fígares I, Rodríguez LC, González-Casado A (2004) Effect of different matrices on physiological amino acids analysis by liquid chromatography: evaluation and correction of the matrix effect. J Chromatogr B 799(1):73-79. doi:10.1016/j. jchromb.2003.10.012

Fitian AI, Nelson DR, Liu C, Xu Y, Ararat M, Cabrera R (2014) Integrated metabolomic profiling of hepatocellular carcinoma in hepatitis $\mathrm{C}$ cirrhosis through GC/MS and UPLC/MS-MS. Liver Int. doi:10.1111/liv.12541

Furtado JD, Campos H, Appel LJ, Miller ER, Laranjo N, Carey VJ, Sacks FM (2008) Effect of protein, unsaturated fat, and carbohydrate intakes on plasma apolipoprotein B and VLDL and LDL containing apolipoprotein C-III: results from the OmniHeart trial. Am J Clin Nutr 87(6):1623-1630

Giordano G, Di Gangi I, Gucciardi A, Naturale M (2012) Quantification of underivatised amino acids on dry blood spot, plasma, and urine by HPLC-ESI-MS/MS. In: Alterman MA, Hunziker P (eds) Amino acid analysis, vol 828. Methods in molecular biology. Humana Press, New York, pp 219-242. doi:10.1007/978-1-61779-445-2_18

Gu L, Jones AD, Last RL (2007) LC-MS/MS assay for protein amino acids and metabolically related compounds for large-scale screening of metabolic phenotypes. Anal Chem 79(21):80678075. doi:10.1021/ac070938b

Guo S, J-a Duan, Qian D, Tang Y, Qian Y, Wu D, Su S, Shang E (2013) Rapid determination of amino acids in fruits of Ziziphus jujubaby hydrophilic interaction ultra-high-performance liquid chromatography coupled with Triple-quadrupole mass spectrometry. J Agric Food Chem 61(11):2709-2719. doi:10.1021/ jf305497r

Held PK, White L, Pasquali M (2011) Quantitative urine amino acid analysis using liquid chromatography tandem mass spectrometry and aTRAQ ${ }^{\circledR}$ reagents. J Chromatogr B 879(26):2695-2703. doi:10.1016/j.jchromb.2011.07.030

Hirayama A, Soga T (2012) Amino acid analysis by capillary electrophoresis-mass spectrometry. In: Alterman MA, Hunziker $\mathrm{P}$ (eds) Amino acid analysis, vol 828. Methods in molecular biology. Humana Press, New York, pp 77-82. doi:10.1007/978-1-61779-445-2_8

Jia S, Kang YP, Park JH, Lee J, Kwon SW (2011) Simultaneous determination of 23 amino acids and 7 biogenic amines in fermented food samples by liquid chromatography/quadrupole time-offlight mass spectrometry. J Chromatogr A 1218(51):9174-9182. doi:10.1016/j.chroma.2011.10.040

Kaspar H, Dettmer K, Chan Q, Daniels S, Nimkar S, Daviglus ML, Stamler J, Elliott P, Oefner PJ (2009a) Urinary amino acid analysis: a comparison of $\mathrm{iTRAQ}^{\circledR}{ }^{\circledR} \mathrm{LC}-\mathrm{MS} / \mathrm{MS}, \mathrm{GC}-\mathrm{MS}$, and amino acid analyzer. J Chromatogr B 877(20-21):1838-1846. doi:10.1016/j.jchromb.2009.05.019

Kaspar H, Dettmer K, Gronwald W, Oefner P (2009b) Advances in amino acid analysis. Anal Bioanal Chem 393(2):445-452. doi:10.1007/s00216-008-2421-1

Kim J-A, Choi H-J, Kwon Y-K, Ryu DH, Kwon T-H, Hwang G-S (2014) 1H NMR-based metabolite profiling of plasma in a rat model of chronic kidney disease. PLoS One 9(1):e85445. doi:10.1371/journal.pone.0085445

Kvitvang HFN, Andreassen T, Adam T, Villas-Bôas SG, Bruheim P (2011) Highly sensitive GC/MS/MS method for quantitation of amino and nonamino organic acids. Anal Chem 83(7):27052711. doi:10.1021/ac103245b

Langrock T, Czihal P, Hoffmann R (2006) Amino acid analysis by hydrophilic interaction chromatography coupled on-line to electrospray ionization mass spectrometry. Amino Acids 30(3):291297. doi:10.1007/s00726-005-0300-z

Le A, Ng A, Kwan T, Cusmano-Ozog K, Cowan TM (2014) A rapid, sensitive method for quantitative analysis of underivatized amino acids by liquid chromatography-tandem mass spectrometry (LC-MS/MS). J Chromatogr B 944:166-174. doi:10.1016/j. jchromb.2013.11.017

Lorenzo MP, Navarrete A, Balderas C, Garcia A (2013) Optimization and validation of a CE-LIF method for amino acid determination in biological samples. J Pharm Biomed Anal 73:116-124. doi:10.1016/j.jpba.2012.03.017

Lu J, Xie G, Jia W, Jia W (2013) Insulin resistance and the metabolism of branched-chain amino acids. Front Med 7(1):53-59. doi:10.1007/s11684-013-0255-5

Ma H, Hasim A, Mamtimin B, Kong B, Zhang H-P, Sheyhidin I (2014) Plasma free amino acid profiling of esophageal cancer using high-performance liquid chromatography spectroscopy. World J Gastroenterol 20(26):8653-8659. doi:10.3748/wjg.v20. i26.8653

Moore S, Spackman DH, Stein WH (1958) Automatic recording apparatus for use in the chromatography of amino acids. Fed Proc 17(4):1107-1115

Morris C, O'Grada C, Ryan M, Roche HM, Gibney MJ, Gibney ER, Brennan L (2012) The relationship between BMI and metabolomic profiles: a focus on amino acids. Proc Nutr Soc 71(04):634-638. doi:10.1017/S0029665112000699 
Namera A, Yashiki M, Nishida M, Kojima T (2002) Direct extract derivatization for determination of amino acids in human urine by gas chromatography and mass spectrometry. J Chromatogr B 776(1):49-55. doi:10.1016/S1570-0232(02)00075-2

Nemkov T, D'Alessandro A, Hansen K (2015) Three-minute method for amino acid analysis by UHPLC and high-resolution quadrupole orbitrap mass spectrometry. Amino Acids. doi:10.1007/ s00726-015-2019-9

Niewczas MA, Sirich TL, Mathew AV, Skupien J, Mohney RP, Warram JH, Smiles A, Huang X, Walker W, Byun J, Karoly ED, Kensicki EM, Berry GT, Bonventre JV, Pennathur S, Meyer TW, Krolewski AS (2014) Uremic solutes and risk of end-stage renal disease in type 2 diabetes: metabolomic study. Kidney Int 85(5):1214-1224. doi:10.1038/ki.2013.497

Paglia G, Hrafnsdóttir S, Magnúsdóttir M, Fleming RT, Thorlacius S, Palsson B, Thiele I (2012) Monitoring metabolites consumption and secretion in cultured cells using ultra-performance liquid chromatography quadrupole-time of flight mass spectrometry (UPLC-Q-ToF-MS). Anal Bioanal Chem 402(3):1183-1198. doi:10.1007/s00216-011-5556-4

Piraud M, Ruet S, Boyer S, Acquaviva C, Clerc-Renaud P, Cheillan D, Vianey-Saban C (2011) Amino acid profiling for the diagnosis of inborn errors of metabolism. In: Metz TO (ed) Metabolic profiling, vol 708. Methods in molecular biology. Humana Press, New York, pp 25-53. doi:10.1007/978-1-61737-985-7_2

Poinsot V, Ong-Meang V, Gavard P, Couderc F (2014) Recent advances in amino acid analysis by capillary electromigration methods, 2011-2013. Electrophoresis 35(1):50-68. doi:10.1002/ elps.201300306

Qu J, Wang Y, Luo G, Wu Z, Yang C (2002) Validated quantitation of underivatized amino acids in human blood samples by volatile ion-pair reversed-phase liquid chromatography coupled to isotope dilution tandem mass spectrometry. Anal Chem 74(9):2034-2040. doi:10.1021/ac0111917

Salazar C, Armenta J, Cortés D, Shulaev V (2012) Combination of an AccQ-Tag-ultra performance liquid chromatographic method with tandem mass spectrometry for the analysis of amino acids. In: Alterman MA, Hunziker P (eds) Amino acid analysis, vol 828. Methods in molecular biology. Humana Press, New York, pp 13-28. doi:10.1007/978-1-61779-445-2_2

Spackman DHSWH, Moore S (1958) Automatic recording apparatus for use in the chromatography of amino acids. Anal Chem 30:1190-1206

Ulijaszek SJ, Kerr DA (1999) Anthropometric measurement error and the assessment of nutritional status. Br J Nutr 82(3):165-177. doi:S0007114599001348 [pii]
US Food and Drug Administration (2001) Guidance for industry bioanalytical method validation. http://www.fda.gov/downloads/ Drugs/Guidances/ucm070107.pdf. Accessed April 2014

Waterval WAH, Scheijen JLJM, Ortmans-Ploemen MMJC, Habetsvan der Poel CD, Bierau J (2009) Quantitative UPLC-MS/ MS analysis of underivatised amino acids in body fluids is a reliable tool for the diagnosis and follow-up of patients with inborn errors of metabolism. Clin Chim Acta 407(1-2):36-42. doi:10.1016/j.cca.2009.06.023

Wiklund PK, Pekkala S, Autio R, Munukka E, Xu LT, Saltevo J, Cheng SM, Kujala UM, Alen M, Cheng SL (2014) Serum metabolic profiles in overweight and obese women with and without metabolic syndrome. Diabetol Metab Syndr. doi:10.1186/1758-5996-6-40

Wu G (2009) Amino acids: metabolism, functions, and nutrition. Amino Acids 37(1):1-17. doi:10.1007/s00726-009-0269-0

Yao X, Zhou G, Tang Y, Pang H, Qian Y, Guo S, Mo X, Zhu S, Su S, Qian D, Jin C, Qin Y, J-a Duan (2013) Direct determination of underivatized amino acids from Ginkgo biloba leaves by using hydrophilic interaction ultra high performance liquid chromatography coupled with triple quadrupole mass spectrometry. J Sep Sci 36(17):2878-2887. doi:10.1002/jssc. 201201045

Yuan M, Breitkopf SB, Yang X, Asara JM (2012) A positive/negative ion-switching, targeted mass spectrometry-based metabolomics platform for bodily fluids, cells, and fresh and fixed tissue. Nat Protoc 7(5):872-881. doi:10.1038/nprot.2012.024

Zang X, Jones CM, Long TQ, Monge ME, Zhou M, Walker LD, Mezencev R, Gray A, McDonald JF, Fernández FM (2014) Feasibility of detecting prostate cancer by ultraperformance liquid chromatography-mass spectrometry serum metabolomics. J Proteom Res 13(7):3444-3454. doi:10.1021/pr500409q

Zhou G, Pang H, Tang Y, Yao X, Mo X, Zhu S, Guo S, Qian D, Qian Y, Su S, Zhang L, Jin C, Qin Y, J-a Duan (2013) Hydrophilic interaction ultra-performance liquid chromatography coupled with triple-quadrupole tandem mass spectrometry for highly rapid and sensitive analysis of underivatized amino acids in functional foods. Amino Acids 44(5):1293-1305. doi:10.1007/ s00726-013-1463-7

Zhou L, Liao Y, Yin P, Zeng Z, Li J, Lu X, Zheng L, Xu G (2014) Metabolic profiling study of early and late recurrence of hepatocellular carcinoma based on liquid chromatography-mass spectrometry. J Chromatogr B 966:163-170. doi:10.1016/j. jchromb.2014.01.057 